\title{
Facial Lipodistrofia In Patients Living with HIV/ AIDS: From Diagnosis to The Necessary Interventions.
}

\author{
Elcio Magdalena Giovani*, Silva AC, Noro Filho GA, Santos CC and Pollo IC \\ Department of Dentistry, Brazil University, Brazil \\ *Corresponding author: Elcio Magdalena Giovani, Chairman, Professor, Integrated Clinic Discipline, Coordinator of Center for \\ Studies and Special Service for Patients, Professor, Postgraduate Dentistry Courses, UNIP, São Paulo, SP, Brazil.
}

To Cite This Article: Elcio Magdalena Giovani. Facial Lipodistrofia In Patients Living with HIV/AIDS: From Diagnosis to The Necessary Interventions. Am J Biomed Sci \& Res. 2019 - 4(3). AJBSR.MS.ID.000795. DOI: 10.34297/AJBSR.2019.04.000795

Received: : July 18, 2019| Published: July 29, 2019

\begin{abstract}
Summary
The advent of Aids has brought new challenges to the health area and the dentist surgeon plays an important role in the management of these patients. Antiretroviral therapy has dramatically changed the morbidity and mortality associated with HIV/Aids infection but has contributed to the emergence of other new situations that require proper approach. Lipodystrophic Syndrome Associated with HIV/AIDS is of multifactorial origin but is strongly associated with the use of antiretrovirals. It comprises alterations in the distribution of body fat, accompanied or not by metabolic alterations. The loss of facial fat, called facial lipoatrophy, is one of the most stigmatizing signs of the syndrome. This condition, often revealing the disease, brought back the stigma of AIDS, leading patients to depression and total seclusion of their daily life activities. It is necessary that Dental Surgeons always share with the multidisciplinary team working with HIV/AIDS patients to identify these changes and seek effective and recommended treatment options for the treatment of facial lipoatrophy associated with HIV/AIDS.
\end{abstract}

Keywords: HIV/AIDS Patients; Lipodystrophic Syndrome; Lipodystrophy; Facial Lipoatrophy

\section{Literature Review}

In HIV/AIDS patients using high-potency antiretroviral therapy, from their Advent, in mid-1996, a series of new anatomical and metabolic changes began to be observed, mainly in showing atrophy of peripheral fat, as well as accumulation of central fat, and simultaneously, it was noted that the redistribution of body fat was accompanied by insulin resistance and several abnormalities in serum lipids. These alterations were described and denominated as lipodystrophy and/or lipodystrophy HIV syndrome (SLHIV).

At the time of the initial diagnosis of lipodystrophic syndrome, the first morphological signs of SLHIV were described in a period of 2 years after the introduction of protease inhibitors (PI), however, it coincides with the inclusion of a second nucleoside analog reverse transcriptase inhibitor, stavudine. Initially, SLHIV was called "Crixbelly", because the first cases ofbody fat redistribution were observed after the use of Crixivan ${ }^{\circledR}$ (indinavir), an IP class medicine. Subsequently, the association between the use of indinavir and the redistribution of body fat is observed, described after the initial diagnosis of the syndrome, described in 1998, where with the imagological resources, the utilization of computed tomography was used, Demonstrating the increase in visceral fat in these individuals. Following the chronological order of time, new PI appear, and clinical and laboratory evidence was observed that the redistribution of body fat was not an exclusive effect of indinavir, and this denomination was abandoned. Nowadays, several synonyms are used for SLHIV, such as body fat redistribution syndrome, metabolic syndrome associated with antiretroviral therapy, or, more recently, dyslipidemic lipodystrophy associated with HIV/HAART [1-7].

Since the first diagnoses of the lipodystrophic syndrome have been made, several body modifications have been pointedout,among them the moststriking were perceived in the face of the accumulation of fat inthe abdominal region and in the posterior part of the neck, called the Gibas. Other important anatomical alterations point to the lipoatrophy of the face, the upper and lower limbs and a prominence of the superficial veins, or not to an accumulation of fats in the region of the abdomen, cervical region and breasts. One of the most used methods to determine a case of lipodystrophy includes the subjective description of changes in body fat, and then 
some diagnostic criteria are proposed, among them the clinicians described as face-back, temples Depressed, clotted eyes, prominent zygomatic arch, slimed aspect, prominent non-varicose veins in arms and legs, loss of skinfolds, loss of contour and fat of the gluteal region. The accumulation of fat is categorized into 5 areas, such as: increased abdominal circumference, pectoral enlargement, buildup of dorsal-cervical fat, accumulating facial fat, and the presence of lipomas. The methods for evaluation and monitoring of fat include patient complaint, clinical assessments, anthropometric measurements and imaging exams.

The lack of standardized values in relation to fat in the general population and the heterogeneity of the clinical manifestations of lipodystrophy make the diagnosis even more difficult, but some methods that have been used are effective and recommended, such as Anthropometry, bio impedance, DEXA, computed tomography, magnetic resonance imaging and ultrasonography. Anthropometry and Impedanciometry are not able to measure regional fat, but the use of Ultrasound becomes important and promising, in the face of its simplicity of not being invasive, and low cost. Epidemiologically scientific research suggests that the percentage of individuals with lipodystrophy is extremely variable among HIV patients, using antiretroviral therapy (ART) for at least one year [1,3,6,8-10].

The metabolic alterations are detected and among them are understood the lipid alterations and abnormalities in glucose homeostasis, and they can still be associated or not the anatomical alterations and the lipid alterations found in the SLHIV, which Are the increase in serum triglyceride levels (GCT) and/or total cholesterol. Hypertriglyceridemia is mainly due to the high rates of new lipogenesis and delayed clearance of GCS in the postprandial period, and a significantly increased proportion of patients using IP, have increased serum levels of Fasting of Apoliproteins B and E, possibly by increased synthesis of the same, which could be related to the manifestation of hyperlipidemia.

Glucose abnormalities may manifest as glucose intolerance, peripheral insulin resistance or diabetes mellitus (DM), and the mechanisms of action by which ARVS, such as protease inhibitors, cause insulin resistance, are the Reduction of insulinmediated glucose uptake in skeletal musculature and adipocytes, affecting glucose metabolism by producing imperfect peroxisome proliferator-activated gamma receptor (PPAR-gamma) expressions. Nucleoside analogous reverse transcriptase inhibitors mainly cause lactic acidosis occurring in the syndrome. Moreover, secondary to mitochondrial dysfunction due to the inhibition of the deoxyribonucleic acid (DNA) Mitochondrial polymerase by this class of drugs. The establishment of lactic acidosis is slow and the symptoms are not specific.

Metabolic alterations are associated with increased risk of cardiovascular events. Hyperinsulinemia associated with insulin resistance and a recognized risk factor in HIV-infected patients and may contribute to the increased risk of acute myocardial infarction in patients receiving ARV. Thus, HIV-positive patients, with a significantly higher prevalence of high levels of fasting glycemia and triglycerides and low levels of HDL cholesterol, have an increased risk of atherosclerosis, coronary disease and diabetes mellitus, which is evident as an expressive pathology associated with lipodystrophic syndrome in patients living with HIV/Aids [1,3-6, 11-13].

There are proposals for adequate interventions for patients with facial lipoatrophy to be established and shared by the multidisciplinary team (dentist, clinical physician, infectologist, endocrinologist, dermatologist, plastic surgeon, Nutritionist, physical educator), being:

a) Change the medication: in a patient receiving HIV treatment with ARVs such as Zidovudine or stavudine, it is recommended to exchange for a nucleoside analogue such as Abacavir, and in patients using PROTEASE inhibitor to evaluate its substitution by an Integrase inhibitor as Dolutegravir.

b) Dietary changes: food restructuring replacing all excesses by low fat and carbohydrate diet.

c) Drug treatment with metformin, glyazones and or human recombinant leptin.

d) Hormonal treatment: Use of supplements and hormones should be evaluated with caution due to the risk of drug interaction and increased risk of hepatitis.

e) Physical activities: Implement physical activity routines preferably at least 3 times a week.

f) Cosmetic Treatments: Facial reconstruction with free flaps or silicone; Liposuction.

Lipectomy to remove excess fat; Methacrylate fillings; and use of buccal prostheses to fill the spaces of the lost dental elements and or even the edentulous, show considerably improvements in the conditions of deformities caused by facial lipoatrophy, alleviating the losses, Patient's facial region [14-19].

\section{Facial Lipoatrophy}

Among the areas affected by lipoatrophy, one of the most frequent components of the syndrome, the face is the region in which fat loss is more evident and impactful. Facial lipoatrophy is defined by a progressive loss of the facial fat, due to the reduction of malar fat called Bichat ball and temporal fat, consequently implying the emergence of new skin grooves and the accentuated increase of Expression Grooves, In addition to areas of depression and evidence of bone structure, which is why it leads to a wrinkle of the face and gives the individual an aspect of premature aging and, in women, the loss of facial fat leads to a loss of the femininity of the face, and the aspect of the face in A "disease facies", returning the stigma of the "face of Aids", in addition to the fear of the unintentional revelation of the diagnosis [3,20-23].

Comparative studies, between the volume deficit in the face resulting from aging caused by alterations in the soft tissues and fat loss occurring in HIV-associated lipoatrophy, suggest that it is lower in aging than that observed in people With Lipoatrophy. However, with advances in the treatment of Aids and the reduction 
of morbidity and mortality, consequently there was an increase in life expectancy and, increasingly, we will have the combination of these two factors (aging and lipoatrophy) interfering directly in the contour Patients living with HIV/Aids.

Another worrying and currently detected factor is the loss of bone mineral density that is part of the same syndrome, and is currently highly researched, since it is increasingly reflected in maintaining special care for dental surgical procedures Avoiding intimely conducts exerting the proposed activities with lightness and safety avoiding fractures and other traumas to the patient, besides the same for the success of the surgical indication of the placement of dental implants, which may be associated with avascular necrosis, it also has to be considered as an important complication of SLHIV, since hyperlipidemia and the infection itself by HIV are known risk factors for osteonecrosis of the femoral head and in mandibles $[1,4,20,24]$.

In the present moment, it evidences a certain tendency of Aids in becoming a chronification-stage disease and associated with the administration of antiretroviral drugs, its use can accelerate the development of facial lipoatrophy, influencing the quality of life in those who Develops. To improve the quality of life of the patient, when the dentist and or the multidisciplinary team itself point to the aforementioned diagnosis of these patients with facial lipoatrophy, it is necessary for the patient to be welcomed, forming an important bond with him in order to receive a look, and special attention and multidisciplinary preference, and ensure the dental treatment, replacing the losses of the dental elements, a factor that decreases the Flattening and or even the sinking caused by lipoatrophy, rescuing the aesthetics, chewing and phonetics, considerably improving the appearance and the posterior when necessary and with indication for each case as a complementary procedure the patient has The possibility of receiving facial filling, completing and correcting the marks of facial lipoatrophy. One of the options for facial filling is polymethylmethacrylate. (PMMA), also botulinum toxin (Botox®) and hyaluronic acid [1,25-29].

The Facial lipoatrophy Index (ILA) was developed an instrument that aims to measure the degree of atrophy and the degree of improvement with the treatment, in an objective way. The ILA evaluates 3 regions of the face, which are:

1) Malar region that corresponds to the areas of the zygomatic and buccal regions, having as limits the infraorbital border and the lower edge of the mandible; The zygomatic bone, the projection of the mandible body, the major zygomatic muscle, the canine fossa and the maxilla.

2) Temporal region corresponds to the anterior portion of the temporal fossa, limited by the temporal line of the frontal bone and the zygomatic arch.

3) The Preauricular region corresponds to the Masseterin region, between the zygomatic arch and the angle and the lower edge of the mandible.

The depth and extent of the affected area in the malar, temporal and pre-auricular regions are evaluated separately. The depth of the atrophic areas is scored from 0 to 4 , being 0 as absence of atrophy, 1 mild depth, 2 moderates, 3 being severe and 4 very severe. The extent of the affected area is scored from 0 to 5 , being 0 as absence of impairment, 1 impairment less than $20 \%$ of the evaluated region, 2 from 21 to $50 \%, 3$ from 51 to $70 \%, 4$ from 71 to $90 \%$ and 5 from 91 to $100 \%$. A partial number is calculated for each area evaluated, multiplying the score relative to the depth by the score relative to the affected area and still by a correction factor. Since fat loss is not symmetrical, it is considered the most affected side in the evaluation.

The Brazilian Ministry of Health uses a classification of facial lipoatrophy in grades I to IV, from the application of the ILA. Being grade I, or mild facial lipoatrophy, and in these cases, there is a slight depression, but there is no evidence of anatomical accidents in the region or loss of facial contour. Grade II, or moderate, is characterized by depression, and is more visible with the onset of the visualization of anatomical accidents, especially the zygomatic arch and the increase of the nasolabial sulcus. Grade III, or severe, where the Malar region's accidents are observed, such as the zygomatic bone, visualization of the canine fossa, partial visualization of the major zygomatic muscle, and mild or moderate depression of the lower edge of the mandible. Loss of facial contour and jaw projection may occur. The degree IV, or very severe, and there is almost complete visualization of the anatomical contours, revealing the bone and muscular framework of the face. There is loss of facial contour, with visualization of the upper and lower faces of the zygomatic arch in the temporal and preauricular regions. Other classifications are adopted in the international literature, all with a degree of subjectivity for being evaluator dependent $[14,17,23,28,30-33]$.

\section{Final Considerations}

With the introduction of high-potency antiretroviral treatment (HAART), in people living with HIV/Aids (PVHA) important and determinant factors such as the decrease in morbidity and mortality and increased life expectancy, with higher quality, began to make Some of the achievements acquired in these years, but on the other hand, a series of adverse events related to the use of medications have been reported. Several clinical signs and symptoms have been described since then and grouped as Lipodystrophic syndrome, which is characterized by anatomical and metabolic alterations, and may occur in isolation or associated form. Metabolic alterations comprise a serum increase in lipids (cholesterol and triglycerides), increased peripheral resistance to insulin, changes in bone trabeculate, type I diabetes mellitus, associated or not with anatomical alterations. These, in turn, derive from the redistribution of body fat, which may result in loss (lipoatrophy) or accumulation (lipohypertrophy).

Lipoatrophy occurs in the region of the face, upper and lower limbs and buttocks. Lipohypertrophy occurs in the abdomen, cervical region and breasts. Dentists together with the multidisciplinary team reveal an important role in this context, as they achieve within their area of knowledge to mitigate these adverse effects of lipoatrophy, as they perform an effective treatment 
Dentistry, mainly by replacing the loss of dental elements that automatically associated with lipoatrophy, somatize irreparable damage. But the placement of oral prostheses replenishing the dental losses, rescuing the loss of the vertical dimension, the phonetics, the aesthetics, and carefully adjusting the prostheses being characterized, making them come to fill the wrinkles and sinks, and may Be complemented with facial filling with botulinum toxin, polymethacrylate and other available options that jointly mitigate all procedures the deleterious effects of facial lipoatrophy. These alterations in the body contour negatively affect mainly the psychosocial health of people living with HIV/Aids, who may have their seropositivity revealed by these remarkable characteristics, which intensify the stigma in relation To the disease, strengthening prejudice, impacting social and affective relationships, directly influencing treatment adherence and even abandonment.

\section{References}

1. Apodaca FR, Molero MJF, Sansinenea E, Magallares FPA, Agirrezabal A (2018) Perceived discrimination, self-exclusion and well-being among people with HIV as a function of lipodystrophy symptoms. Annals of Psychology 34(1): 7-15.

2. Bednasz C, Luque Ae, Zingman Bs, Fischl Ma, Gripshover Bm, et al. (2016) Lipid-Lowering Therapy in HIV-Infected Patients: Relationship with Antiretroviral Agents and Impact of Substance-Related Disorders. Curr Vasc Pharmacol 14(3): 280-287.

3. Feleke Y, Fekade D, Mezegebu Y (2012) Prevalence of highly active antiretroviral therapy associated metabolic abnormalities and lipodystrophy in HIV infected patients. Ethiop Med J 50(3): 221-230.

4. Finkelstein JL, Pooja Gala P, Rochford R, Glesby MJ, Saurabh Mehta S (2015) HIV/AIDS and lipodystrophy: Implications for clinical management in resource-limited settings. J Int AIDS Soc 18(15): 19033.

5. MA Q Zingman BS, Luque AE, Fischl MA, Gripshover BM, Venuto CS, et al. (2011) Therapeutic drug monitoring of protease inhibitors and efavirenz in HIV-infected individuals with active substance-related disorders. Ther Drug Monit 33(3): 309-314.

6. Singano V, Amberbir A, Garone D, Kandionamaso C, Msonko J, et al. (2017) The burden of gynecomastia among men on antiretroviral therapy in Zomba, Malawi. PLOS one 12(11): e0188379.

7. Valeriano JJLS (2019) Polimorfismos genéticos associados an efeitos adversos neuropsiquiátricos em pacientes HIV positivos submetidos À terapia com Efavirenz.

8. (2015) GNP+, ICW and UNAIDS. The people living with HIV stigma index.

9. Viskovic K, Richman I, Klasnic K, Hernandez A, Krolo I, Rutherford GW (2009) Assessment of Ultrasound for Use in Detecting Lipoatrophy in HIV-Infected Patients Taking Combination Antiretroviral Therapy. Aids Patient Care 23(2): 79-84.

10. Warde M, Gragnani A, Gomes H, Hochman B, Ferreira LM (2011) The impact of facial lipoatrophy treatment with polymethyl methacrylate in AIDS patients as measured by four quality-of-life questionnaires. Int J STD AIDS 22(10): 596-599.

11. Connolly M, Siddique I, Nusrath M (2017) Journal of the Irish Dental Association Journal Downloaded 12:45:00

12. Lira Neto JCG, Oliveira JFSF, Souza MA, Araújo MFM, Damasceno MMC, et al. (2018) Prevalence of the metabolic syndrome and its components in people with type 2 diabetes mellitus Enferm. Florianópolis Epub 27(3).

13. Maggi P, Di Biagio A, Rusconi S, Cicalini S, D’abbraccio M, et al. (2017) Cardiovascular risk and dyslipidemia among persons living with HIV: a review. BMC Infect Dis 17(1): 551.
14. Bassichetto K, Piloto HF (2002) Roteiro de atendimento ambulatorial de nutrição para adultos vivendo com HIV/AIDS. Journal Brasileiro de Aids 3(1): 07-31.

15. Carr A, Emery S, Law M, Puls R, Lundgren JD, Powderly WG (2003) An objective case definition of lipodystrophy in HIV-infected adults. Lancet 361(9359): 726-735.

16. Jones D (2005) HIV facial lipoatrophy causes and treatment options. Dermatol Surg 31(11Pt 2): 1519-1529.

17. (2009) Ministério Da Saúde Secretaria De Vigilância Em Saúde. Departamento De Dst, Aids E Hepatites Virais. Manual de tratamento da lipoatrofia facial: recomendações para o preenchimento facial com polimetilmetacrilato em portadores de HIV/AIDS. Série A. Normas e Manuais Técnicos. Ministério da Saúde, Brasil.

18. (2009) Programa De DST/AIDS E Hepatites Virais De São Bernardo Do Campo-SP, Protocolos de Preenchimentos do Ambulatório de Lipodistrofia, portaria Conjunta SAS/SVS no 01, de 20 de Janeiro de.

19. Soares FMG, Costa IMC (2013) Treatment of HIV-associated facial lipoatrophy: impact on infection progression assessed by viral load and CD4 count. A Bras Dermatol 88(4): 570-577.

20. Van Griensven J, De Naeyer L, Mushi T, Ubarijoro S, Gashumba D, et al. (2007) High prevalence of lipoatrophy among patients on stavudinecontaining first-line antiretroviral therapy regimens in Rwanda. Trans $\mathrm{R}$ Soc Trop Med Hyg 101(8): 793-798.

21. Kadouch JA, Van Rozelaar L, Karim RB, Hoekzema R (2013) Current treatment methods for combination antiretroviral therapy-induced lipoatrophy of the face. Int J STD AIDS 24(9): 685-694.

22. Soares FMG, Costa IMC (2013) Lipoatrofia facial associada ao HIV/AIDS: do advento aosconhecimentos atuais / HIV-Associated facial lipoatrophy: from the advent to current knowledge A Bras Dermatol 88(4): 570-577.

23. Burkat CN, DE Niro JE (2016) HIV-associated facial lipoatrophy. American Academy of Ophthalmology.

24. Marc-Antoine V, Aubron-Olivier C, Jade G, Elisabeth L, Pauchard M, Hélène S, et al. (2003) Polylactic acid implants (New-Fill) ® to correct facial lipoatrophy in HIV-infected patients: results of the open-label study VEGA AIDS 17(17): 2471-2477.

25. Martins WH, Pessôa Kvo, Martins MA, Silva MH, Pereira Filho GV, Abreu LC (2016) Facial filling with polymethylmethacrylate in patients with acquired immunodeficiency syndrome. Revista Brasileira de Cirurgia Plástica 31(2).

26. Moyle GJ, Lysakova L, Brown S, Sibtain N, Healy J, et al. (2004) A randomized open-label study of immediate versus delayed polylactic acid injections for the cosmetic management of facial lipoatrophy in persons with HIV infection HIV Medicine. British HIV Association 5(2): 82-87.

27. Piquet M, Brignol L, Chatelain B, Rey D, Ricbourg B, et al. (2007) Polylactic acid injections: usefulness for the treatment of facial lipoatrophy in HIV+ patients under tritherapy. Rev Stomatol Chir Maxillofac 108(6): 496504.

28. Weldegebreal F, Mitiku H, Teklemariam Z (2016) Magnitude of adverse drug reaction and associated factors among HIV-infected adults on antiretroviral therapy in Hiwot Fana specialized university hospital, eastern Ethiopia Pan Afr Med J 24: 255.

29. Serra MS, Gonçalves LZ, Ramos-E-Silva M (2015) Soft tissue augmentation with PMMA-microspheres for the treatment of HIV-associated buttock lipodystrophy. Int J STD AIDS 26(4): 279-284.

30. Oguntibeju 00 (2012) Quality of life of people living with HIV and AIDS and antiretroviral therapy. HIV AIDS (Auckl) 4:117-124.

31. Osei-Yeboah J, Owiredu Wkba, Norgbe GK, Lokpo SY, Obirikorang C, et al. (2017) Quality of Life of People Living with HIV/AIDS in the Ho Municipality, Ghana: A Cross-Sectional Study. AIDS Res Treat 2017: 6806951. 
32. Fields-Gardner C (2010) American Dietetic Association (ADA) Position of the American Dietetic Association: Nutrition Intervention and Human Immunodeficiency Virus Infection. J Am Diet Assoc 110(7): 1105-1119.
33. Gkrania-Klotsas E, Klotsas AE (2007) HIV and HIV treatment: effects on fats, glucose and lipids. Br Med Bull 84: 49-68. 